\title{
A lógica da essência
}

João Alberto Wohlfart

HEGEL, Georg Wilhelm Friedrich. A doutrina da Essência. V. 2. Equipe de Tradução: Tradutores: Christian G. Iber e Federico Orsini. Coordenador: Agemir Bavaresco; Colaboradores: Marloren L. Miranda e Michela Bordignon. Revisor: Francisco Jozivan G. de Lima. Petrópolis, RJ: Vozes; Bragança Paulista, SP: Editora Universitária São Francisco, 2017, pp. 271.

Veio a lume a tradução do segundo volume da Ciência da Lógica intitulado "A Doutrina da Essência”, uma tradução realizada por Christian Iber, Federico Orsini, resultante de um trabalho em equipe coordenado pelo professor Agemir Bavaresco. O belo livro que temos em mãos integra a coleção de obras filosóficas denominada Pensamento Humano, editado e publicado pela Editora Vozes. Com esta tradução, os falantes de língua portuguesa e os estudantes de filosofia de todos os níveis têm em mãos uma obra fundamental do pensamento hegeliano para a leitura, abordagem em aula, produções filosóficas e aprofundamento do conhecimento da filosofia hegeliana, especialmente no Brasil. Para os que lemos uma das principais obras filosóficas da história, durante anos, no idioma do filósofo Hegel, agora temos a agradável surpresa de ter em mãos este texto difícil na nossa língua portuguesa.

Esta tradução já fora antecipada pela tradução do primeiro volume da Ciência da Lógica, a Doutrina do Ser, e a sua adequada leitura e compreensão deve ser antecipada pela leitura do primeiro volume. A Doutrina do Ser termina com o círculo categorial da desmedida, portanto na abstração e na indeterminação universal, sem que nada possa ser determinado e diferenciado em relação a outras coisas. Por este viés, a primeira questão a ser abordada por Hegel na Doutrina da Essência é a

${ }^{1}$ Instituto Superior de Filosofia Berthier < joao@fabemarau.edu.br > 
determinação e diferenciação das coisas, o estabelecimento do estatuto lógico da multiplicidade e da diversidade. Do ser para a essência qual a indeterminação universal do ser mergulha na interioridade de sua reflexão, o que resulta no revestimento do ser por determinações concretas.

Hegel, na Doutrina da Essência, não ressuscita a velha noção metafísica de essência e não se apropria da sua noção kantiana, mas submete a metafísica tradicional a uma radical crítica. Dualismos metafísicos de toda a espécie são demolidos, aplainados e integrados num mesmo círculo relacional no qual cada polaridade subsiste na outra e pela outra. De modo geral, a Doutrina da Essência pode ser interpretada como uma crítica radical, demolidora e destruidora da metafísica tradicional, dos dualismos clássicos, do pensamento moderno e das formas estáticas de pensamento. Desta forma, ao longo deste volume da Ciência da Lógica são unificados dialeticamente binômios como essência e aparência, condicionado e incondicionado, necessidade e contingência, substância e acidente, absoluto e relativo, substância e interação etc. Ao longo da exposição hegeliana, estes opostos vão sendo progressivamente integrados, dissolvidos em outros níveis de pensamento, ao mesmo tempo em que o filósofo vai expondo a mais profunda crítica filosófica até então conhecida, especialmente no processo de dissolução de estruturas consagradas da metafísica tradicional.

O livro não é apenas surpreendente no seu processo de exposição, com uma linguagem filosófica dificilmente compreensível a partir de uma simples leitura, mas surpreende com um olhar atento do índice do livro. A segunda parte que trata do aparecimento surpreende porque sinônimos como aparência e fenômeno não são mais interpretados como contrários à razão, mas a aparência se torna uma dimensão fundamental da própria razão. Neste sentido, uma das novidades fundamentais da Doutrina da Essência é a introdução, como constitutiva da razão, de uma dimensão que sempre lhe foi negada. Com esta abordagem hegeliana, não há mais nenhum fundamento inabalável para a razão, nem de ordem metafísica, ou teológica, ou lógica, mas a razão se autofundamenta no seu próprio caminho de constituição, de forma que a Lógica hegeliana não tem o recurso a uma esfera exterior a ela.

A Doutrina da Essência apresenta uma trilogia dialética constituída pela essência, pelo aparecimento e pela efetividade. Cada uma destas 
seções é também tripartite, na essência estruturada em aparência, nas determinações da reflexão e no fundamento; o aparecimento estruturado em existência, em aparecimento e em relação essencial; a efetividade estruturada em absoluto, na efetividade e na relação absoluta. Para traduzir em palavras simples o significado filosófico das três seções da Doutrina da Essência, a essência se refere às determinações imanentes da essência, tais como a identidade, a diferença e o fundamento; o aparecimento se refere à exteriorização da essência, especialmente na destruição da coisa, na interação entre as coisas e na relação essencial; a efetividade se refere ao substancial processo de aparecimento da razão, especialmente na lógica das modalidades e no sistema da relação absoluta, no qual conclui a Doutrina da Essência. Em toda a trajetória desta exposição, conceitos opostos vão se integrando, se alternando, e a razão como um todo se constitui através do processo de mediação. Assim, com a incorporação do aparecimento como constitutivo da razão, ela se transforma num movimento sistêmico de negação e de constituição.

A primeira seção da Doutrina da Essência trata das determinações da reflexão, especialmente a identidade, a diferença e a contradição. Talvez, nesta seção compreendemos a razão para se escrever uma Doutrina da Essência, não para legitimar a clássica noção de essência, mas para dissolvê-la por completo. Por este viés, não existe mais uma simples noção de identidade na clássica fórmula $\mathrm{A}=\mathrm{A}$, com a exclusão do outro, mas a identidade somente é tal com a inclusão da diferença. Ela somente pode ser explicada e fundamentada pela diferença, pois somente algo é idêntico pela sua diferenciação em relação à alteridade, e a diferença somente é tal diante da identidade. Na formulação hegeliana, identidade e diferença se compenetram mutuamente, pois a identidade se constitui diante da diferença, e a diferença é identidade consigo mesma e diferença em relação à identidade. Por seu curso, a identidade é diferença em relação à diferença, de modo que, identidade e diferença, cada qual, é duplamente constituída pela identidade e pela diferença. Neste raciocínio, cada uma destas determinações somente é pela outra, pois cada uma é refletida em si mesma a partir de seu outro. As várias modalidades de diferença expostas por Hegel são a diferença absoluta, a diversidade, a oposição e a contradição, pois a diferença absoluta diz respeito à relação da diferença em relação a si mesma, na medida em que absolutamente tudo estabelece relação com a sua diferença. 
Hegel estabelece a unidade entre a identidade e a diferença na categoria de fundamento. Para Hegel, fundamento não significa uma base incondicionada e imóvel sobre a qual é edificada uma consequência ou uma causalidade segunda linearmente deduzida do fundamento primeiro, mas o fundamento constitui o círculo relacional entre a identidade e a diferença. $\mathrm{O}$ fundamento caracteriza uma espécie de totalidade relacional segundo a qual todas as coisas são idênticas consigo mesmas na medida em que se diferenciam, e tudo se diferencia na identidade. Trata-se, portanto, de uma extensão universal de interpenetração entre a identidade e a diferença, pois estas duas determinações da essência se encontram distribuídas por tudo. O fundamento, portanto, não é mais a identidade originária e absoluta de algo que exclui de si a alteridade, mas caracteriza a universal interpenetração da identidade e da diferença. Para Hegel, "a essência, na medida em que ela se determina como fundamento, determina-se como o não determinado, e somente o suprassumir de seu ser determinado é seu determinar-se" (93). Desaparece, em Hegel, a noção clássica de essência como algo determinado e específico, para dar lugar à indeterminação universal capaz de integrar os opostos como um círculo de autofundamentação universal. Neste sentido, se todas as coisas são confluência de identidade e de diferença, o fundamento constitui a estrutura universal integradora e sintetizadora de tudo.

Hegel expõe várias expressões e desdobramentos da categoria fundamento. A primeira delas é fundamento absoluto, em binômios categoriais como forma e essência, forma e matéria, forma e conteúdo. Nesta modalidade de fundamento, o primeiro é a condição e o segundo é o condicionado e a essência é o fundamento do aparecimento, da efetividade, enfim, o fundamento incondicionado de toda a Ciência da Lógica. A segunda modalidade de fundamento é fundamento determinado, expressa na necessidade de determinação geral e múltipla nas diferentes dimensões da razão e da realidade. Em outras palavras, o fundamento somente é tal na medida em que se expressa e se determina numa condição fundada, enquanto o fundamento é restringido pela condição de sua determinação. A terceira modalidade de fundamento é o fundamento completo, desdobrado no relativamente incondicionado e no incondicionado absoluto. Esta última modalidade é a bilateralidade relacional entre condição e condicionado, pois a condição se determina diante do condicionado, e o condicionado contém em si mesmo a condição. 
A noção hegeliana de incondicionado absoluto não fixa uma dimensão diante da outra como polos irredutíveis e excludentes, mas desencadeia-se uma determinação recíproca entre condição e condicionado. Mesmo que não seja esta a problemática abordada por Hegel nesta seção, por exemplo, Deus somente pode ser considerado como absoluto e incondicionado se o homem o determina como absoluto na sua capacidade de pensá-lo e conhecê-lo.

A essência passa dialeticamente para o aparecimento. A noção hegeliana da essência não a deixa escondida num espaço numinoso e impenetrável, atrás das aparências, mas a essência deve aparecer na forma da diferença e da exterioridade. Desta forma, o aparecimento não significa uma expressão posterior e superficial de uma essência imóvel e incomunicável, mas no aparecer a essência se determina e põe as suas determinações racionais no processo de aparecimento. Para Hegel, "mas este ser, em que a essência se transforma, é o essencial, a existência; um ser que saiu da negatividade e da interioridade" (143). O aparecimento não é uma manifestação posterior e secundária, mas no aparecimento a essência se determina como essência, na condição dialeticamente qualificada da existência. Trata-se de um movimento de saída da interioridade abstrata e superficial, porque a existência é estruturada no equilíbrio entre a interioridade e a exterioridade, num contínuo processo de exteriorização e de interiorização, em níveis nos quais estes dois movimentos se integram e se diferenciam em novas configurações. $\mathrm{Na}$ noção hegeliana de aparecimento, fenômeno e existência têm em comum a lógica do movimento, porque nada mais pode ser interpretado como simplesmente dado, mas todas as determinações de racionalidade, mesmo as de caráter estritamente ontológicas e essencialistas, são resultado de um movimento de aparecimento.

A existência, tal como exposta por Hegel, pode ser considerada como uma densificação e universalização do fundamento, na dialética entre a mediação e o mediado. Mediação e mediado constituem-se reciprocamente na posição da mesma realidade. Assim, "a mediação através do fundamento se suprassume, mas não deixa o fundamento embaixo, de modo que aquilo que surge dele seria um posto, o qual teria sua essência em outro lugar, a saber, dentro do fundamento, mas esse fundamento, enquanto abismo, é a mediação desaparecida” (137). Desaparece a relação unilateral entre fundamento e fundado, entre 
mediação e mediado, de modo que o que é fundado é portador da mesma fundamentação que o fundamento, ou seja, a mediação determina o mediado da mesma forma que o mediado determina a mediação. A noção hegeliana de existência, exposta nesta parte da Doutrina da Essência, forma uma espécie de abismo universal reintegrador e unificador de todos os dualismos metafísicos clássicos e kantianos, na condição de uma existência preenchida. Assim, ficou suprassumida a noção de essência enquanto fundamento da existência e do fenômeno, e o fundamento enquanto determinação primeira ficou positivado no fundamento universal. Em termos teológicos e religiosos, apenas para exemplificar, Deus não é mais uma transcendência inatingível pelo conhecimento finito, mas o abismo universal também preenchido e mediado pelo conhecimento humano.

Esta argumentação converge num aspecto estruturante no universo da Ciência da Lógica. Refere-se a um item intitulado por Hegel "a destruição da coisa”, pois ali o filósofo quebra com um dos dogmas fundamentais da velha metafísica sustentada em coisas densas, incomunicáveis e impenetráveis, e as dissolve numa espécie de configuração de relações. Coisas fixas são dissolvidas e substituídas por um movimento universal de interpenetração de matérias e de intercruzamento de movimentos de organização. De mônadas incomunicáveis, as "coisas" se transformam em polos abertos pelos quais e através dos quais outras matérias perpassam e o universo material é suprassumido num sistema universal de intercâmbio material. Assim, em todas as coisas são compreendidas múltiplas outras coisas, de forma que Hegel atualiza um fundamento clássico de racionalidade dialética segundo o qual "tudo está em tudo" e tudo está implicado em tudo. Isto expõe o princípio segundo o qual em cada coisa elementar está compreendida a totalidade, estruturada a partir da dialética do microcosmos e do macrocosmos, da elementaridade e da totalidade, do simples e do complexo etc. Para Hegel, "essa dissolução é um tornar-se determinado externo, tal como também o ser da mesma; mas sua dissolução e a exterioridade e seu ser é o essencial desse ser; ela é somente o também; ela consiste somente nesta exterioridade” (150). Para Hegel, as coisas não são constituídas na identidade própria, num conjunto de predicados que constituem o seu ser absoluto e incomunicável, mas são constituídas pela exterioridade de outros materiais e movimentos externos. Em outras 
palavras, uma coisa não é a identidade de si mesma, mas uma coisa é a sua própria exterioridade e diferença, em cujo movimento é muito mais forte e intensiva a heterodeterminação e heteronomia que a autodeterminação.

A Ciência da Lógica, especialmente na Doutrina da Essência, procede duplamente um caminho de destruição e de construção. Na segunda seção da Doutrina da Essência, que trata do aparecimento, Hegel destrói a essência e a aparência, mas suprassume estas determinações destruídas por uma configuração racional mais elevada e mais complexa. A pergunta é esta: qual seria a síntese mais elevada entre a essência e a aparência destruídas? Se Hegel destruiu o que sempre foi considerado como existente necessário, a essência metafísica, o que efetivamente existe? A resposta hegeliana a esta questão está no terceiro capítulo da segunda seção, a relação essencial. A relação dissolve e suprassume a essência e a aparência porque, por um lado, é constituído um sistema global no interior do qual tudo está relacionado, pois o que é fundamental em tudo e em todas as coisas são as relações que estabelecem. Nesta configuração, nada é imediatamente idêntico consigo mesmo, mas a relação é a unidade entre a referência a si mesmo e a referência a outro, pois na referência a outro se torna referente a si mesmo. Nesta sistemática, cada coisa ou sujeito está constitutivamente aberto a múltiplos outros sujeitos, e entre todas as coisas e sujeitos se estabelece um sistema de relação universal no qual todas as coisas estão relacionadas com todas as coisas, cada coisa e cada sujeito se relacionam com a totalidade e a totalidade com cada coisa, enquanto todas as coisas se constituem no interior da teia infinita e complexa que é a totalidade. Para Hegel, "ela é, portanto, algo quebrado dentro de si mesmo; mas esse seu ser suprassumido consiste no fato de que ela é a unidade de si mesma e de seu outro, portanto, um todo, e justamente por isso ela tem existência autossubsistente e é reflexão essencial dentro de si” (172).

Hegel fecha a Doutrina da Essência com a terceira seção dedicada à efetividade, qualificada como unidade dialética entre interioridade e exterioridade, essência e aparência. A efetividade não deve ser entendida como o resultado de uma reflexão anterior produtora de um efeito, mas enquanto unidade de essência e aparecimento, ela se determina como um movimento reflexivo de autodeterminação e autodesenvolvimento universais, na forma de aparecimento sistêmico e permanente. Hegel, como nas partes anteriores, estrutura esta seção na trilogia dialética 
composta por "o absoluto", "a efetividade" e "a relação absoluta". Evidencia-se, nesta parte, uma teoria sobre o absoluto, numa densíssima exposição que vai além de todas as abordagens e formulações já realizadas até então pela História da Filosofia. Nesta construção, o absoluto é inseparável de um sistema de relações conjugada em binômios dialéticos como necessidade e contingência, substancialidade e acidentalidade, absoluto e relativo, substancialidade e relacionalidade. Para Hegel, "a identidade do absoluto é, por conseguinte, a identidade absoluta, pelo fato de que cada uma de suas partes é, ela mesma, o todo, ou seja, cada determinidade é a totalidade" (194). O absoluto não é verticalmente sobreposto ao mundo relativo e contingente, mas o absoluto é a totalidade universal internamente estruturado por um sistema de determinações no qual cada determinidade é a totalidade. Isto significa dizer que cada uma está mergulhada no abismo universal do absoluto como todas as outras, razão pela qual todas elas convergem em cada uma como configuração densificada de um sistema de relações. Vale aqui a proposição neoplatônica segundo a qual tudo está em tudo e por meio de tudo num sistema de interpenetração universal, como um movimento de singularização da totalidade e de totalização da singularidade. Para Hegel, "mas o próprio absoluto é a identidade absoluta; essa é a sua determinação, na medida em que toda a multiplicidade do mundo que é em si e do mundo que aparece ou da totalidade interior e exterior está suprassumida nele" (194). Não há uma exterioridade fora o absoluto ou uma manifestação externa rebaixada, tal como a noção criacionista cristã na qual o mundo está fora do absoluto, mas uma universalidade sistemática ilimitada que suprassume num único universo a interioridade e a exterioridade.

Dentro desta lógica, Hegel expõe o atributo do absoluto e o modo do absoluto. $\mathrm{O}$ atributo do absoluto não caracteriza dois lados de sua estrutura imanente, tais como o essencial e o inessencial, o númeno e o fenômeno, mas o atributo absoluto caracteriza simplesmente o absolutamente absoluto. Para Hegel, "dentro do absoluto, pelo contrário, essas imediatidades diferentes são rebaixadas à aparência, e à totalidade, que é o atributo, é posta como seu subsistir verdadeiro e único; mas a determinação, na qual ele é, está posta como o inessencial” (197). Os atributos não representam, para Hegel, diferenças qualitativas substancialmente diferentes entre si e, por consequência, incomunicáveis, mas as diferenças internas se tornam inessenciais na medida em que estão 
mergulhadas na mesma substancialidade universal. A curiosa inessencialidade indiferente universal é idêntica à essencialidade absoluta, pois, como veremos logo abaixo, a intercomunicação universal de todas as coisas produz uma espécie de substancialidade indiferente na qual as diferenças de coisas mergulham na indiferença global. Enquanto o atributo do absoluto produz a sua interiorização como lógica da identidade absoluta, o modo absoluto produz a exteriorização e a diferenciação, na radical cisão e contradição interna. Para Hegel, "o absoluto é a forma absoluta, a qual, como a cisão de si, é pura e simplesmente idêntica consigo, o negativo como negativo, ou aquilo que se junta consigo e somente assim é a identidade absoluta consigo, que igualmente é indiferente frente a suas diferenças ou é conteúdo absoluto; o conteúdo é, portanto, somente esta própria exposição" (199). A negação da identidade absoluta se dá na radical cisão enquanto o seu conteúdo é automanifestação, não no sentido de que o conteúdo da essência se manifesta em determinadas formas exteriores, mas no movimento de identificação da forma e do conteúdo como automanifestação absoluta. A autocontradição de si mesma enquanto autonegação passa a ser a identidade através da qual o absoluto se automediatiza consigo mesmo como exposição de si.

No capítulo segundo, Hegel expõe a lógica das modalidades, um dos capítulos muito estudados de toda a literatura hegeliana. Para Hegel, "então, como a manifestação de que não tem outro conteúdo e não é nada mais do que o fato de ser sua manifestação, o absoluto é a forma absoluta. A efetividade tem de ser tomada como esta absolutidade refletida" (205). A lógica das modalidades tem como significação fundamental a forma absoluta da manifestação, distribuída na possibilidade e necessidade formais; na necessidade relativa ou efetividade, possibilidade e necessidade reais; e na necessidade absoluta. De modo geral, Hegel não expõe uma necessidade cega que elimina a diferença, a multiplicidade, a possibilidade e a contingência, como, num outro plano, a História estaria conduzida por uma causalidade inexorável onde tudo estaria incondicionalmente predeterminado. A noção hegeliana de necessidade absoluta se dá porque passa a ser constitutiva da racionalidade a contingência e a multiplicidade. Não se trata de uma lógica que elimina a contingência, mas o que propriamente é absoluto é a ciranda e a dança das modalidades e a metamorfose de uma modalidade nas outras. Para Hegel, 
“[...] suas diferenças não são, por conseguinte, como determinações da reflexão, mas sim como multiplicidade que é, como efetividade diferenciada, que tem a figura de outros autossubsistentes uns frente aos outros" (218). Na multiplicidade, as modalidades são determinadas umas frente às outras, são reciprocamente mediadas num sistema absoluto, o que resulta na identidade absoluta internamente diferenciada na transformação da efetividade em possibilidade e da possibilidade em efetividade. Não se trata, portanto, da necessidade absoluta que elimina a contingência, mas o movimento entre a possibilidade, a contingência, a multiplicidade, a realidade e a efetividade resultam na necessidade absoluta.

Hegel conclui a Doutrina da Essência com um capítulo sobre a relação absoluta. Trata-se de um capítulo decisivo na Ciência da Lógica como um todo, no pensamento hegeliano e na literatura filosófica universal. Como Hegel expõe uma lógica da contradição, a relação absoluta aparece como a expressão máxima da contradição e da Doutrina da Essência como um todo. A descoberta fundamental da Doutrina da Essência agora se torna plena, ao conjugar dialeticamente a absoluticidade e a relatividade. Nesta lógica, a relatividade se torna absoluta em função da interrelacionalidade global de todas as coisas que constituem o sistema do absoluto propriamente dito, e o absoluto se torna relativo em função da autorrelação universal consigo mesmo na autorreflexão. A dissolução da coisa enquanto metafísica da mônada incomunicável e impenetrável resultou no conceito de relação absoluta na qual todas as coisas são essencialmente interconectadas entre si no interior da totalidade do absoluto, de forma que a relatividade tem a mesma abrangência e profundidade da absolutidade. Para Hegel, "a essência enquanto tal é a reflexão ou o aparecer; mas a essência enquanto relação absoluta é a aparência posta como aparência, a qual, como esse relacionar consigo, é a efetividade absoluta" (221). Conforme observamos acima, agora a essência não se exterioriza mais num fenômeno posterior e superficialmente relacionado ao fundamento imóvel, mas a relação absoluta aparece no movimento e aparência universal, como autorrelação absoluta e efetividade absoluta. Em outras palavras, as sólidas e dinâmicas relações entre a multiplicidade variada de coisas se universaliza no movimento e na aparência quee resulta na autorreflexividade do absoluto. Em suma, poderia se afirmar que o resultado da Doutrina da Essência é a relatividade 
universal, a ponto de absolutizar a relatividade, numa espécie de manifestação da efetividade absoluta igual a si mesma.

A primeira forma de relação absoluta é a relação de substancialidade efetivada na implicação de imanência entre substancialidade e acidentalidade. A substancialidade se desdobra na multiplicidade de acidentes e os acidentes se organizam na imanência da substancialidade. Para Hegel, "o aparecer é o aparecer que se relaciona consigo, assim ele é; este ser é a substância como tal. Inversamente, este ser é apenas o ser posto idêntico consigo, assim ele é a totalidade que aparece, a acidentalidade" (222). A substancialidade aparece como a autorreflexividade do aparecimento que se traduz no sistema de acidentalidades em totalização reflexiva. Nesta perspectiva, a substancialidade é a absoluta atuosidade em autocontradição de si mesmo manifestada na coextensividade entre destruição e criação, pois a força da substancialidade cria na medida em que destrói, e destrói na medida em que cria. A relação de substancialidade se transforma em relação de causalidade porque a absoluta atuosidade tem como resultado a produção do efeito. Na verdade, causa e efeito constituem a mesma realidade da autocausalidade da substância.

A Doutrina da Essência conclui com a categoria da interação. A relação de substancialidade e a relação de causalidade desaparecem e dão lugar à interação. Segundo Hegel, "inicialmente, a interação apresenta-se como uma causalidade recíproca de substâncias pressupostas que se condicionam, cada uma é, frente à outra, substância ativa e passiva ao mesmo tempo" (238). Entre as diversas substâncias estabelece-se uma interação que consiste na causalidade recíproca entre uma e outra; numa multiplicidade indeterminada de substâncias em causalidade recíproca; cada substância singular é causada pela totalidade de substâncias; cada substância individual causa a totalidade substancial. Esta multilateralidade interacional e interconectividade universal produz uma força de interação no interior da qual as múltiplas substâncias estão mergulhadas como um complexo sistema relacional. A imagem adequada para expressar este sistema é a rede, na qual cada nó representa uma substância e os fios indicam as múltiplas conexões com e entre as substâncias. Aliás, as substâncias desaparecem como autônomas e se transformam em configurações de relações por onde converge e atravessa todo o movimento interacional da totalidade do sistema. Hegel subverte a 
tradição ao proporcionar dinamicidade e densidade substancial às relações e transformar em fenômeno as "coisas" individuais. Para Hegel, "a necessidade é o ser porque ele é, - a unidade do ser consigo mesmo, o qual tem por si o fundamento; mas, inversamente, porque ela tem um fundamento, não é ser, é pura e simplesmente aparência, relação ou mediação" (239). As múltiplas substâncias não têm o fundamento nelas mesmas e são exteriormente relacionadas entre si, mas a relacionalidade e interrelacionalidade universal é a substância no interior da qual tudo é mediatizado com tudo. Agora, as substâncias se transformam em elos de relação e em aparências, pois são formas diferenciadas de aparecimento do mesmo sistema universal que se diferencia internamente em várias formas de densificação relacional.

Não pode ser esquecida a passagem da Doutrina da Essência para a Doutrina do Conceito. Na última parte do texto sobre a interação Hegel dá importantes pistas sobre esta passagem, caracterizada especialmente pela passagem da causalidade e da necessidade na lógica da liberdade, da autodeterminação e da intersubjetividade. Hegel mesmo aponta que o mais difícil caminho é o da passagem na necessidade na liberdade, da causalidade na autodeterminação, da substancialidade no conceito. Neste caminho dialético, a relação de substancialidade é suprassumida na universalidade do conceito, na inteligibilidade conceitual que permanece idêntica consigo mesma na multiplicidade. A relação de causalidade é suprassumida pela particularidade do conceito enquanto autodesenvolvimento e autodeterminação imanente que forma a totalidade do conceito. Nesta exposição, a universalidade é inseparável da diferenciação imanente, pois, pelo caminho inverso, a universalidade ficaria suspensa num plano transcendente e reduzida a uma mera particularidade formal e vazia. A interação é suprassumida na singularidade do conceito como um círculo que reconduz a estrutura da racionalidade dialética da particularidade para a universalidade, na condição da universalidade concreta.

A Doutrina da Essência vai muito além da sua estrutura interna sinteticamente reconstruída acima. Ela contém dentro de si uma crítica profunda e demolidora dos dualismos metafísicos tradicionais e uma crítica ao pensamento moderno, especialmente de Kant e de Espinosa. Hegel mostra que o pensamento filosófico não é constituído por monumentos fixos e determinados neles mesmos, mas todas as formas de 
pensamento filosófico constituem aparências de um movimento universal. Além de estabelecer a passagem dialética para a Lógica do Conceito, a Doutrina da Essência vai muito além dela, estendendo as suas luzes para as contemporâneas Teorias da Complexidade e dos Sistemas. A compreensão do mundo atual, da natureza, da sociedade e do Universo como um complexo sistema relacional, como um sistema de sistemas complexos interrelacionados, tem a sua matriz fundamental na Doutrina da Essência hegeliana. É o marco referencial da Lógica, da Epistemologia e da Ontologia de uma época, acrescido do movimento dialético e processual de constituição destes sistemas. A Doutrina da Essência pode ser considerada como a mediação fundamental entre o modelo clássico, metafísico e dogmático de pensamento e o modelo contemporâneo relativista e pragmatista de pensamento. Isto se sustenta porque Hegel constrói um sistema dinâmico dialeticamente articulado, com momentos estruturantes neste processo de construção. 